Submission \#11633

\title{
Intuition in Strategic Decision Making: Implications for Strategic Decision Effectiveness
}

\begin{abstract}
Intuition can produce effective strategic decisions because of its speed and ability to solve less-structured problems. Despite this, there are only a very small number of empirical studies that have examined intuition in the strategic decision-making process. We examine the relationship between the use of intuition in the strategic decision-making process, and strategic decision effectiveness. We propose that the expertise of the decision-maker, environmental dynamism and the characteristics of the strategic decision itself moderate the relationship between the use of intuition in the strategic decision making process, and strategic decision effectiveness. We make a significant theoretical contribution by integrating the management and social-psychology literatures in order to identify the variables that affect the relationship between the use of intuition in the strategic decision-making process, and strategic decision effectiveness. This article builds upon existing empirical research that has examined intuition in the strategic decision-making process, and reconciles some of the confounding results that have emerged. The paper presents a conceptual model and research propositions, which if empirically examined, would make a significant contribution to knowledge in the strategic decision-making domain of literature.
\end{abstract}

\section{Keywords:}

Strategic decision making; intuition; strategic decision effectiveness 
Submission \#11633

\section{INTRODUCTION}

The strategic decision making process (SDMP) takes place in an external environment characterised by increasingly fierce competition, shortening product life-cycles, rapid technological innovation and economic turbulence (Nadkarni \& Herrmann, 2010). How decision makers make effective strategic decisions under these conditions is of critical importance to management researchers and practioners, and some compelling arguments have been advanced regarding the efficacy of the use of intuition in the SDMP. This is because under such conditions, the use of intuition in the SDMP enables decision-makers to rapidly assess a situation, integrate and synthesise huge amounts of data, and deal with incomplete information (Khatri \& Ng, 2000). Thus, intuition speeds up the SDMP. The speed of the SDMP is critical in certain environments (Eisenhardt, 1989) and due to information being limited or unavailable, intuitive SDMPs using soft information may produce effective strategic decisions (SDs) (Mintzberg, 1994a; 1994b). This is because instead of spending time searching for information that may not exist, is inaccurate, or becomes obsolete rapidly; decision-makers with expertise are instead able to use their intuition, which operates subconsciously and functions by quickly scanning for cues and then matching these cues with previous experiences, in order to arrive at a decision (Quinn, 1980; Wally \& Baum, 1997).

A considerable amount conceptual literature exists arguing the benefits of intuition in strategic decision-making (e.g. Akinci \& Sadler-Smith, 2011; Dane \& Pratt, 2007; 2009; SadlerSmith \& Shefy, 2004; Sinclair, Sadler-Smith \& Hodgkinson, 2009). However, empirical evidence to support a relationship between the use of intuition in the SDMP and SD 
effectiveness is lacking. One particularly important theoretical gap concerns the effects that contextual variables have on the relationship between the use of intuition in the SDMP and the effectiveness of the SD. This gap is especially notable because of the significant effects that contextual variables have been found to have on the use of other processes in the SDMP such as rationality and politics, and SD effectiveness (Brouthers, Brouthers \& Werner, 2000; Elbanna \& Child, 2007a; Papadakis, Lioukas \& Chambers, 1998). The extent to which the use of intuition in the SDMP will result in effective SDs depends on three contextual variables: (i) the expertise of the decision-maker; (ii) environment dynamism, and; (iii) the characteristics of the SD (whether the SD is familiar, uncertain, or time pressured) (Dane \& Pratt, 2007; Kahneman \& Klein, 2009; Salas, Risen \& Diaz Granados, 2010). Expertise is crucial, because intuition will be most effective when the decision-maker is knowledgeable and experienced (Hogarth, 2001). Environmental dynamism and the characteristics of the SD are of importance because they will determine whether reliably identifiable cues are available, the extent to which relationships between cues can be determined, and whether decision makers can predict the likely outcomes of their decisions (Kahneman \& Klein, 2009).

By examining the moderating effects of decision-maker expertise, environmental dynamism and the characteristics of the SD, this article addresses calls in the literature that have stated the urgent need for research identifying the factors that affect the relationship between the use of intuition in the SDMP and SD effectiveness (Dane \& Pratt, 2007; Khatri \& Ng, 2000; Sinclair et al, 2009). As Salas, Rosen \& DiazGranados, (2010: 966) succinctly state: “the time for a science of intuition in organizations capable of guiding practice and improving effectiveness has come.” 
Submission \#11633

\section{THEORETICAL BACKGROUND}

Strategic decision making (SDM) is the responsibility of the top management team (Elbanna, 2006). SDs are inherently uncertain; they address issues which are infrequent, unusual and non-routine, and they rarely have one optimal solution (Stahl \& Grigsby, 1992; Wilson, 2003). SDs involve the commitment of substantial resources, set precedents that are often impossible to reverse and that shape the firm's direction (Dean \& Sharfman, 1996; Mintzberg, Raisinghani \& Theoret, 1976). SDs critically affect the health and survival of the organization (Eisenhardt \& Zbaracki, 1992).

\section{The Strategic Decision-Making Process}

Due to the magnitude of impact that SDs have upon the organization, as well as their complex and judgmental nature, a number of authors contend that rational strategic decision making processes (SDMPs) should be utilized in order to make effective SDs (e.g. Elbanna \& Child, 2007a; 2007b; Dean \& Sharfman, 1996; 1993; Fredrickson \& Mitchell, 1984; Goll \& Rasheed, 1997; Hough \& White, 2003). This is because through the systematic gathering and analysis of information, gaps in the decision maker's knowledge and understanding can be filled and a more comprehensive understanding of the context of a SD can be developed in order to mitigate uncertainty (Dean \& Sharfman, 1996; Goll \& Rasheed, 2005). Studies that have examined the use of rational SDMPs have however produced conflicting results (Elbanna, 2006). Furthermore, authors have suggested that because of the characteristics of the external environment (e.g. dynamism) and the characteristics of the SD itself (e.g. if it is unfamiliar, uncertain, and time pressured) it may not be possible to make effective strategic decisions using 
rational SDMPs because decision makers lack the required computational skills, have difficulty in identifying cause-and-effect relationships, and information can often be unavailable, incomplete or becomes obsolete rapidly (Baum \& Wally, 2003; Hough \& White, 2003; Sinclair et al 2009).

The use of intuition in the strategic decision-making process. Some authors have suggested that intuition should be used in the SDMP because it will produce effective SDs when the decision-maker has expertise, the external environment is dynamic and the strategic decision is familiar, uncertain, and time pressured (Akinci \& Sadler-Smith, 2011; Dayan \& Elbanna, 2011; Eisenhardt, 1989; Khatri \& Ng, 2000; Miller \& Ireland, 2005; Sinclair et al, 2009; Stubbart, 1989). This is because intuition enables decision makers to make rapid, holistic associations and draw together disparate pieces of information non-consciously to provide a clear view of how to proceed with a particular SD (Dane \& Pratt, 2007). Intuition, compared to rationality has the advantages of requiring less resources and being fast; rationality struggles to deal with discrepant information as it is troublesome to determine the weighting of such information (Bingham \& Eisenhardt, 2011).

Intuition has been cited as both a cognitive process (e.g. Jung, 1933; Westcott \& Ranzoni, 1963) as well as an outcome of a process (e.g. Rorty, 1967) however here it is considered to be a cognitive process and intuitions are defined as "affectively charged judgments that arise through rapid, nonconscious, and holistic associations” (Dane \& Pratt, 2007: 40). 
Despite the recent interest in intuition in management theory, including several articles that have clarified the concept (e.g. Dane \& Pratt, 2007; 2009; Epstein, 2010; Hodgkinson, Langan-Fox \& Sadler-Smith, 2008), empirical research on intuition in SDM is scarce (Khatri \& $\mathrm{Ng}, 2000$ ). There is however an urgent need for theory development in this area because it is unclear under what conditions the use of intuition in the SDMP will result in effective strategic decisions (Elbanna \& Child, 2007a). Several calls in the literature have been made for research that examines the conditions under which intuition results in effective strategic decisions (e.g. Dane \& Pratt, 2009; Khatri \& Ng, 2000; Salas, Rosen \& DiazGranados, 2010). In order to address this gap in the SDM literature, a synthesis across the SDM literature, as well as the broader management literature (e.g. marketing, organizational behaviour) and the socialpsychology literature is required because theory development has occurred outside of the SDM domain of literature that contains invaluable insights that can be utilized to inform further research in this important area. Furthermore, there have been explicit calls for this, for example Hough \& ogilvie (2005: 418) state that "to advance the field, we need more studies of strategic decision makers based on literature from psychology”. Integrating these literatures reveals that opinion is divided as to whether the use of intuition in the SDMP can produce effective strategic decisions. For example, some authors in the management literature such as Khatri \& Ng (2000) and Dayan \& Elbanna (2011) have found the use of intuition in the SDMP to result in positive outcomes (such as organizational performance and new product development success). However, other authors, such as those in the social-psychology domain of literature are more sceptical of intuition in SDM and (Kahneman \& Klein, 2009: 521) state that the "business literature celebrates successful leaders who made strategic decisions on the basis of gut feelings 
and intuitions that they did not adequately check, but many of these successes own more to luck than to genius".

A review of the SDM, organizational behaviour, marketing and social-psychology literature reveals that he relationship between the use of intuition in the SDMP and the effectiveness of the SD is dependent upon three factors: (i) The level of expertise of the decision maker (Salas et al, 2010); (ii) environmental dynamism (Kahneman \& Klein, 2009), and; (iii) the characteristics of the strategic decision itself (Dayan \& Elbanna, 2011). The level of expertise of the decision maker is important because experts have complex domain-relevant schemas, and intuition relies upon these schemas to quickly identify cues and match them to information stored in the long term memory in order to make a strategic decision (Drillings \& Serfaty, 1997). When the decision maker is a novice, they may still have compelling intuitions; however, they are unlikely to result in effective strategic decisions (Kahneman, 2011). Environmental dynamism is important because it determines whether reliably identifiable cues are available, and the extent to which relationships between cues can be determined and whether decision makers can predict the likely outcomes of their decisions (Kahneman \& Klein, 2009). Furthermore, the characteristics of the SD, in terms of its familiarity, uncertainty and the extent to which it is time pressured will affect the ability of decision-makers to identify cues and the relationships between these cues, and match them to information stored in their long term memory in the timeframe required. 
Submission \#11633

\section{Two Perspectives of the use of Intuition in the Strategic Decision-Making Process}

There are two divergent perspectives regarding whether the use of intuition in the SDMP will result in effective SDs. One perspective suggests that intuition use in the SDMP will result in effective SDs, particularly when the external environment is dynamic and the strategic decision is familiar, uncertain and time pressured. Researchers argue this is because intuition has the advantage over rational SDMPs by being rapid, and able to cope effectively with uncertainty and incomplete and disparate information (Burke \& Miller, 1999; Khatri \& Ng, 2000; Klein, 2003; Orasanu \& Connolly, 1995).

However, the alternative perspective suggests that the use of intuition in the SDMP is unlikely to result in effective SDs when the external environment is dynamic and the strategic decision is unfamiliar and uncertain. This is because there will be an absence of recognisable cues, an inability to reliably identify the relationships between cues and uncertainty over the outcomes of SDs (Kahneman \& Klein, 2009). This perspective suggests that the use of intuition is unlikely to result in effective SDs when there are dynamic stimuli, where problems are not predictable, tasks are unique, and analysis is subjective (Shanteau, 1992). Given the conflict, research identifying the conditions under which the use of intuition results in effective SDs is required as a matter of urgency in order to reconcile these perspectives.

By identifying the conditions under which the use of intuition in the SDMP results in effective SDs, this article makes a significant contribution to knowledge. Furthermore, by simultaneously taking into account three contextual variables (the decision maker, the external 
environment, and the strategic decision) this article also addresses the need for more comprehensive conceptual models of the SDMP that simultaneously examine multiple contextual variables in order to identify which contextual variable has the most significant effect, as well as the interactions between these variables (Brouthers et al 2000; Elbanna \& Child, 2007a; 2007b; Papadakis, Thanos \& Barwise, 2010; Papadakis, Lioukas \& Chambers, 1998; Papadakis \& Barwise, 1997).

The remainder of this article synthesises the SDM literature, as well as the management and social-psychology literature (see figure 1) in order to identify how the expertise of the decision-maker, the external environment and the characteristics of the strategic decision affect the relationship between the use of intuition in the SDMP and the effectiveness of the SD. A theoretical model and testable research propositions are also presented.

\section{Insert Figure 1 about here}

\section{THEORY DEVELOPMENT AND RESEARCH PROPOSITIONS}

This section of the article synthesises the literature relating to each of the variables in the theoretical model (see figure 2 below), and states testable research propositions.

Insert Figure 2 about here 
Submission \#11633

\section{The Relationship between the Use of Intuition in the Strategic Decision-Making Process and Strategic Decision Effectiveness}

Intuition. Intuition functions via the decision maker's system 1 , also referred to as the experiential system, (Epstein, 1994; Kahneman, 2003). System 1 cognitive processes are automatic, subconscious, involve emotions and feelings and synthesize information holistically (Epstein, Pacini, Heier \& Denes-Raj, 1996). System 2 (also referred to as the rational system) by contrast, is conscious, analytic, intentional, and free of emotion (Epstein et al, 1996). System 1 and system 2 are in fact complementary and one mode can override the other in order to correct a decision (Kahnemann, 2003). The degree of dominance of one system is contingent upon individual preferences, the characteristics of the task, the degree of emotional involvement, and the experience of the decision maker (Epstein et al, 1996). Recent studies in the social cognitive neuroscience domain of literature have demonstrated that system 1 and the intuitions it produces have a biological basis, and are produced via neural mechanisms in the ventro-medial prefrontal cortex region of the brain (Chassy \& Gobet, 2011; Hodgkinson, Sadler-Smith, Burke, Claxton \& Sparrow, 2009; Lieberman, 2000). Finally, intuition is often confused with other related concepts such as insight and instinct; Appendix A delineates intuition from related concepts.

Strategic decision effectiveness. Strategic decision effectiveness is defined as "the extent to which a decision achieves the objectives established by management at the time it is made” (Dean \& Sharfman, 1996: 372). Examining SD effectiveness is important because managers and researchers are "vitally interested” in improving the effectiveness of SDs (Hough \& ogilvie, 2005: 418). 
Instead of strategic decision effectiveness, some researchers have examined organizational performance as a dependent variable in studies of SDM (Forbes, 2007). However, Elbanna (2006: 15) states that "outcome measures should be consistent with the unit of analysis...if the study examines isolated strategic decisions, the overall economic performance of an organization may only bear a weak relationship to any individual decision; therefore, decision outcomes such as decision quality or effectiveness will be more appropriate.”

The choice of SD effectiveness as a dependent variable therefore provides for a close link between the SDMP and its outcomes and also avoids the causal ambiguity associated with organizational performance being used as a dependent variable (Dean \& Sharfman, 1996; Elbanna \& Child, 2007a).

Finally, objective measures of SD effectiveness, such as financial performance outcomes are a problematic choice of dependent variable because it is difficult to isolate the financial performance outcomes of certain strategic decisions, such as corporate restructuring (Amason, 1996). Therefore, "the best way to measure the effectiveness of an individual SD is to ask the people who make the decision, observe its effects and comprehend its context, to judge, retrospectively and on several dimensions, how the decision turned out” (Elbanna, 2003: 131).

Only one prior study has empirically investigated the relationship between the use of intuition in the SDMP and SD effectiveness; and Elbanna \& Child (2007a) were unable to find 
support for their hypothesis that the use of intuition would be negatively related to SD effectiveness. This contradicts the study of Khatri \& Ng (2000), who found intuition to be positively related to organizational performance in certain industries. However, these studies are not amenable to direct comparison due to significant differences in the dependent variable used and the national context in which they take place; Elbanna \& Child's 2007a and 2007b's studies were undertaken in Egypt, where many organizations were Government controlled until recently.

Whether or not the use of intuition can result in effective strategic decisions divides opinion amongst researchers (Dane, 2011). Several authors have advocated that intuition is well suited to making effective SDs (e.g. Dane \& Pratt, 2007; Khatri \& Ng, 2000). However, other authors have urged caution, suggesting that the use of intuition in SDM may result in severely biased decisions and will not therefore produce effective SDs (Elbanna \& Child, 2007b; Kahneman \& Klein, 2009). The pessimistic view of intuition is associated with the heuristics and biases perspective which favors a skeptical attitude toward intuition and highlights its fallibility (Kahneman \& Klein, 2009). Both the social-psychology and SDM literature identify situations where the use of intuition can result in systematic and severe biases (e.g. Duhaime \& Schwenk, 1985; Kahneman, 2003; Schwenk 1984). Indeed, in circumstances where the decision-maker lacks expertise or where there are not stable relationships between objectively identifiable cues and subsequent actions, or between cues and the outcomes of possible actions, then it is likely that the decision-maker is relying on heuristics (also referred to as cognitive biases), which is considered to be a type of intuition (Dane \& Pratt, 2007; Kahneman \& Klein, 2009). Examples of heuristics used in SDM include illusion of control, where the decisionmaker over-estimates their own ability to control outcomes; hindsight bias, where decision- 
makers see events that have already occurred as being more predictable than they were before they took place, and; law of small numbers where decision makers over-estimate the degree to which a small sample is representative of the population (Schwenk, 1988).

The heuristics and biases perspective (Kahneman, 2003; Tversky \& Kahnemann, 1974) of intuition is contested by some authors and it is claimed that the researchers adopting this perspective have examined intuition in laboratories and on problems best suited to analysis and logic (Sinclair, 2010). Indeed, those in favour of intuition argue that it can result in effective SDs because it exploits a decision maker's knowledge of the context, which laboratory research does not take into account (Bingham \& Eisenhardt, 2011). In reality, the use of intuition in the SDMP is unlikely to be entirely free from faults (Dunwoody, Haarbauer, Mahan, Marino \& Tang, 2000). However, it may result in effective SDs because it functions best in complex decision making where decision-makers do not have the capacity to process all information consciously (Dijksterhuis, 2004) and intuition can therefore act as an associative and approximate process (Epstein, 1998; Hodgkinson \& Healey, 2011; Sinclair \& Ashkanasy, 2005). Therefore, the preceding arguments suggest the following proposition:

P1: The use of intuition in the strategic decision-making process will be positively related to strategic decision effectiveness. 
Submission \#11633

\section{Decision Maker Expertise}

"Expertise is at the root of effective intuitive decision making in complex organizational settings" (Salas et al, 2010: 942). An expert is defined as "the distinguished or brilliant journeyman, highly regarded by peers, whose judgments are uncommonly accurate and reliable, whose performance shows consummate skill or economy of effort, and who can deal effectively with certain types of rare or tough cases. Also, an expert is one who has special skills or knowledge derived from extensive experience with sub-domains.” Chi (2006: 22).

Expertise is critical in determining whether the use of intuition in the SDMP will result in effective strategic decisions because experts have complex domain relevant schemas developed through extensive learning and experience (Hogarth, 2001). Complex domain relevant schemas contain "knowledge about a concept or type of stimulus, including its attributes and the relations among those attributes” (Fiske \& Taylor, 1991: 98). Experts therefore have a large number of patterns stored in their long term memory (Simon, 1987). The complex domain relevant schemas of experts enable system 1 to rapidly detect important cues and match them to patterns that are stored in the long term memory in order to make an effective strategic decision (Dane \& Pratt, 2007; Hodgkinson et al, 2008).

Contrary to popular belief, expertise does not derive from innate abilities; rather, it is the result of an individual acquiring complex skills and making physiological adaptations (Ericsson \& Charness, 1994). No correlation has been found between IQ and expertise, as such; experts are made rather than born (Bloom, 1985; Ericsson, Prietula \& Cokely, 2007). Research within 
Submission \#11633

the social-psychology and behavioural neuroscience domains of literature has demonstrated that complex skills and physiological adaptations are developed through deliberate practice (Chassy \& Gobet, 2011). Deliberate practice is a type of practice whereby the individual undertakes tasks within a specific domain that are beyond their current level of competence and comfort (Ericsson et al, 2007). Ten years of repeated and intensive deliberate practice is generally considered to be the minimum time period required for expertise to develop (Simonton, 2006). The development of expertise also requires timely, accurate and precise feedback so that the individual knows the results of their endeavours, and can make the necessary adaptations in order to improve future performance. Therefore, it is the combination of pro-longed exposure to a domain, deliberate practice and feedback that enables expertise to develop.

Despite the fundamental importance of expertise in determining the effectiveness of intuition, existing empirical studies of intuition in SDM have not included this variable and focused instead on organization, environmental or decision specific contextual variables (e.g. Elbanna \& Child, 2007a and Khatri \& Ng, 2000). Dayan \& Elbanna’s (2011) examination of intuition in new product development utilizes experience as a proxy for expertise. However, authors have warned against using experience stating that "there are many examples of professionals with considerable experience who never become experts...At best, experience is an uncertain predictor of degree of expertise. At worst, experience reflects seniority - and little more” (Shanteau, Weiss, Thomas \& Pounds, 2002: 254). Furthermore, a major limitation which has been stated about SDMP research, is the so called "black box criticism" (Lawrence, 1997: 2). The "Black Box" criticism highlights that demographics, such as experience, commonly used in SDMP research are not an adequate proxy for the underlying cognitive traits and processes of the 
TMT (Hough \& ogilvie, 2005; Kiduff, Anglemar \& Mehra, 2000; Priem, Lyon \& Dess, 1999). Hambrick \& Mason (1984: 204) state that: “demographic factors simply do not provide a reliable portrayal of a person's makeup. People are more complex than that". This further reinforces the need to measure the decision-maker's expertise rather than experience.

It may be the case that in some circumstances, true expertise cannot develop, such as in irregular or unpredictable environments. This is because of the inability to receive accurate and timely feedback. Kahneman \& Klein (2009: 524) warn against the perils of this "individuals will sometimes make judgments and decisions that are successful by chance. These lucky individuals will be susceptible to an illusion of skill and overconfidence...The financial industry is a rich source of examples." However, where true expertise has had the opportunity to develop, then the more experience and knowledge that the decision-maker has, the better intuition will be at detecting important cues in the environment and matching them to patterns stored in the long term memory in order to make effective SDs (Salas et al, 2010). Therefore, the preceding arguments suggest the following proposition:

P2: Expertise will moderate the relationship between the use of intuition in the strategic decision making process, and strategic decision effectiveness such that the relationship will be stronger when the decision-maker has high levels of expertise. 
Submission \#11633

\section{Environmental Dynamism}

A dynamic environment is one "with a highly unpredictable and unstable rate of change and high levels of uncertainty about the state of the context, the means-ends relationships, and/or the outcomes of the actions.” (Mitchell, Shepherd \& Sharfman, 2011: 687). Environmental dynamism has been studied in the context of SDM because it captures the degree, frequency and unpredictability of change that typify modern environments (Farjoun \& Levin, 2011).

In the presence of environmental dynamism there are multiple SD options, all with uncertain outcomes (Dess \& Beard, 1984), and information rapidly becomes obsolete, and may be incomplete or unavailable (Baum \& Wally, 2003; Hough \& White, 2003). Mitchell et al (2011) assert that environmental dynamism induces a form of SDM characterised by diminished use of information and a narrowing of the attention of the strategic decision maker. Thus, "intuition, as an associative process, may help to integrate the disparate elements of such problems into a coherent perception of how to proceed” (Dane \& Pratt, 2009: 15). Khatri \& Ng (2000) state that the use of intuition in such environments may result in effective SDs because "hard information” may be unreliable or limited and as such using intuition to draw upon previously learned information is likely to result in effective SDs. The rapid nature of intuition (Dane \& Pratt, 2007; Khatri \& Ng, 2000) means that its use in the SDMP may result in effective SDs in dynamic environments because SD speed is of critical importance in such environments (Baum \& Wally, 2003; Eisenhardt 1989; Judge \& Miller, 1991). 
Submission \#11633

Other authors have suggested that intuition should be used in dynamic environments because rationality is unlikely to result in effective SDs in dynamic environments because the information gathered and analysed is likely to be contradictory and slow the SDM process (Hough \& White, 2003). However, simply because rationality may be of little benefit in a dynamic environment, it does not necessarily follow that the use of intuition in the SDMP will result in effective strategic decisions. Kahnemann \& Klein’s (2009) and Shanteau's (1992) arguments suggest that there is unlikely to be a positive relationship between the use of intuition in the SDMP and SD effectiveness in the presence of environmental dynamism because strategic decision makers will not be able to recognize cues in order to recall patterns and information stored in the long term memory. Kahnemann \& Klein (2009) label such environments "zero validity" environments because of the absence of valid cues for strategic decision makers. Intuition is only likely to result in an effective strategic decision if the task environment is "high validity", that is "there are stable relationships between objectively identifiable cues and subsequent events or between cues and the outcomes of possible actions...predictions of the future values of stocks and long-term forecasts of political events are made in a zero validity environment” (Kahneman \& Klein, 2009: 524). Environmental dynamism, using Mitchell et al’s (2011) definition, would not appear to meet the criteria for a valid environment prescribed by Kahneman \& Klein (2009). As such, SDs made using intuition in dynamic environments are likely to be biased and based on heuristics because of an inability to detect reliable cues and relationships between cues, and the uncertainty of SD outcomes. In the presence of environmental dynamism the system 1 will still function, and decision-makers will still have compelling intuitions. However, these may be biased, and based on heuristics such as illusory correlations (beliefs that unrelated variables are correlated); selective perceptions (where 
expectations bias observations of variables relevant to the SD), and; illusion of control, where decision-makers over-estimate their personal control over outcomes (Schwenk, 1988).

However, the case for the use of intuition in the strategic decision-making process resulting in effective strategic decisions in the presence of environmental dynamism is compelling. This is due to the speed of intuition, and its ability to detect subtle cues and holistically synthesise disparate information. Therefore, the preceding arguments suggest the following proposition:

P3: Environmental dynamism will moderate the relationship between the use of intuition in the strategic decision making process and strategic decision effectiveness such that the relationship will be stronger when there are high levels of environmental dynamism.

\section{Strategic Decision Characteristics}

SD characteristics are defined as the labels and categories that strategic decision makers attribute to a strategic decision based upon their perceptions of stimuli (Papadakis et al, 1998). Despite the fact that the characteristics of the SD have not been studied exhaustively in the SDM literature, in the studies that have featured them, they have been found to profoundly affect the SDMP (Elbanna \& Child, 2007a; 2007b). In this section familiarity, uncertainty and time pressure are examined, and their effect on the relationship between the use of intuition in the 
strategic decision-making-process and strategic decision effectiveness is explicated. Several authors have conceptualized that these SD characteristics will determine the effectiveness of intuition (e.g. Dane \& Pratt, 2007; Kahneman \& Klein, 2009; Salas et al, 2010).

Familiarity. The familiarity of a SD is defined as it's frequency of occurrence (Papadakis et al, 1998). When a certain type of SD has been made a number of times, the decision-maker develops complex schemas that contain substantial knowledge about the stimuli associated with the decision, as well as the relationships between the stimuli (Fiske \& Taylor, 1991). Therefore, when the SD is familiar, intuition will produce effective SDs as it will be able to recognise cues and match it to an extensive amount of information held in the long-term memory (Simon, 1992). Familiarity is an important component of several conceptualisations of intuition, including Simon’s (1987: 63) notion of intuition as being analysis “frozen into habit”, and intuition being the non-conscious and automatic application of rules and patterns that decision-makers have learnt (Hayashi, 2001). Therefore, the preceding arguments suggest the following proposition:

P4: Strategic decision familiarity will moderate the relationship between the use of intuition in the strategic decision making process and strategic decision effectiveness, such that the relationship will be stronger when the strategic decision is familiar. 
Uncertainty. Uncertain strategic decisions lack clarity over the actions to be taken, and the information required (Sonenshein, 2007). Uncertain SDs are therefore judgmental and lack objective criteria and demonstrable solutions (Elbanna \& Child, 2007a).

Several authors have posited that when the SD is uncertain, intuition produces effective SDs because intuition will be able to link disparate pieces of information together, match stimuli to knowledge stored in the memory, and form holistic associations based on salient features detected in the environment (Dane \& Pratt, 2009; Dane \& Pratt, 2007; Khatri \& Ng, 2000; Salas et al, 2010). Uncertain SDs are negatively associated with rationality in the SDMP because SD uncertainty is "related to factors that simply cannot be known" (Dean \& Sharfman, 1993: 593).

In the only study that the authors are aware of that examines the effect of SD uncertainty on the relationship between intuition use in the SDMP and SD effectiveness, Elbanna \& Child (2007a) found no support for the hypothesised moderating effect of SD uncertainty. However, uncertain SDs are complex, and require the use of judgment, making them particularly amenable to the use of intuition (Burke \& Miller, 1999; Dane \& Pratt, 2007; Salas et al, 2010). Kahneman \& Klein (2009: 520) assert that "high validity does not imply the absence of uncertainty", and cite the example of chess masters who utilize intuition to make effective decisions despite the uncertainty created by the enormous number of possible developments in a chess game. Therefore, the preceding arguments suggest the following proposition: 
Submission \#11633

P5: Strategic decision uncertainty will moderate the relationship between the use of intuition in the strategic decision making process and strategic decision effectiveness, such that the relationship will be stronger when the strategic decision is uncertain.

Time pressure. If the SD is time pressured then intuition may produce effective SDs due to its speed (Kaempf, Klein, Thorsden, \& Wolf, 1996; Klein, 1998) as it requires much less information gathering and analysis activity than rationality does (Baum \& Wally, 2003; Dean \& Sharfman, 1993; Khatri \& Ng, 2000). A fundamental characteristic of intuition is its ability to rapidly match cues in the environment to information stored in the long term memory "allowing an individual to know almost instantly what the best course of action is" (Khatri \& Ng, 2000: 61). The ability to make SDs under time pressure is important for organizational performance (Bourgeois \& Eisenhardt, 1988), and Eisenhardt (1989) found that decision-makers utilize intuition in order to make simultaneously rapid and effective strategic decisions. However, Eisenhardt's (1989) findings are based on eight organizations, and empirical evidence based on larger samples is required (Papadakis \& Barwise, 1997). Therefore, the preceding arguments suggest the following proposition:

P6: The time pressure associated with the strategic decision will moderate the relationship between the use of intuition in the strategic decision making process and strategic decision effectiveness, such that the relationship will be stronger when the strategic decision is time pressured. 
Submission \#11633

\section{SUMMARY}

This article has proposed that the relationship between the use of intuition in the SDMP and SD effectiveness is moderated by the following contextual variables: decision-maker expertise; environmental dynamism, and; the characteristics of the strategic decision.

By empirically examining the proposed relationships in this paper a significant theoretical contribution can be made to the SDM domain of literature. Compelling arguments have been put forward by researchers as to how the use of intuition in the SDMP can result in effective SDs (e.g. Dane \& Pratt, 2007) due to its ability to cope with uncertainty and integrate disparate and incomplete information rapidly in order to form a decision. However, empirical evidence to support the conceptual work on intuition is lacking, and that which does exist is contradictory. The research proposed in this article can resolve these discrepancies. Undertaking a comprehensive literature review across the SDM, organizational behaviour, marketing and social-psychology literature reveals the importance of expertise in determining whether the use of intuition results in effective SDs. However, existing studies of intuition in SDM have not included any measure of expertise. Furthermore, this integrative literature review has revealed tensions regarding whether environmental dynamism will strengthen (e.g. Khatri \& Ng, 2000) or weaken (e.g. Kahneman \& Klein, 2009) the relationship between the use of intuition in the SDMP and SD effectiveness. This article also highlights how the characteristics of the strategic decision profoundly affect the relationship between the use of intuition in the SDMP and SD effectiveness. 
Finally, this article also addresses two other criticisms of the existing SDM literature in that it has used demographics as proxies for the underlying cognitive processes and content of decision-makers; and that existing SDM research has not simultaneously examined different contextual variables. 


\section{Figure 1: Overview of Empirical Research}

\begin{tabular}{|c|c|c|}
\hline & $\begin{array}{l}\text { Strategic Decision Making Domain of } \\
\text { Literature } \\
\text { Intuition (e.g. Eisenhardt, 1989; Khatri } \\
\text { \& Ng, 2000) } \\
\text { Cognitive Style (e.g. Hough \& ogilvie, } \\
\text { 2005) } \\
\text { Cognitive biases (e.g. Hodgkinson et al, } \\
\text { 1999) }\end{array}$ & \\
\hline $\begin{array}{l}\text { Marketing Domain of Literature } \\
\text { Decision Making (e.g. Wierenga, 2011) } \\
\text { Cognitive biases (e.g. Mahajan, 1992) } \\
\text { Experience (e.g. Perkins \& Rao, 1990) }\end{array}$ & $\begin{array}{c}\text { Research Gap } \\
\text { An Examination of } \\
\text { Intuition in Strategic } \\
\text { Decision Making: } \\
\text { Implications for Strategic } \\
\text { Decision Effectiveness }\end{array}$ & $\begin{array}{l}\text { Social-Psychology Domain of Literature } \\
\text { Heuristics \& biases (e.g. Tversky \& } \\
\text { Kahneman, 1974) } \\
\text { Naturalistic decision making (Klein, } \\
\text { Calderwood \& Clinton-Cirocco, 2010) } \\
\text { Expertise (Ericsson et al, 2006) } \\
\text { Intuition (Hodgkinson et al, 2009) }\end{array}$ \\
\hline & $\begin{array}{l}\frac{\text { Organizational Behaviour Domain of }}{\text { Literature }} \\
\text { Expertise (e.g. Shanteau, 1992) } \\
\text { Intuition (e.g. Dane \& Pratt, 2007; } \\
\text { 2009) } \\
\text { Cognition (e.g. Walsh, 1995) }\end{array}$ & \\
\hline
\end{tabular}


Figure 2: Theoretical Model

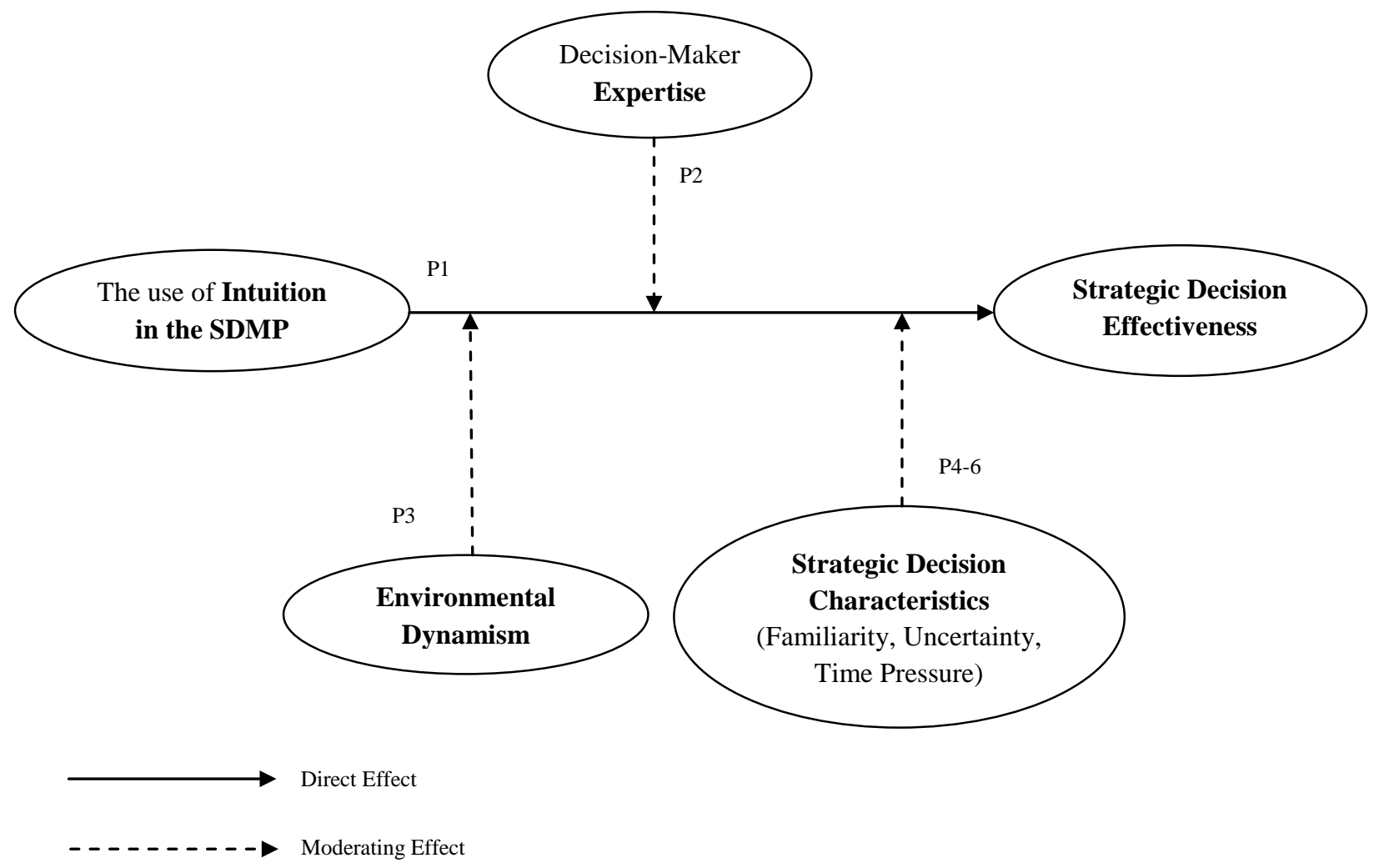




\section{APPENDIX A}

\section{Table 1: Delineating Intuition from Related Concepts}

\begin{tabular}{|c|c|}
\hline Concept & $\begin{array}{c}\text { Definition and Delineation } \\
\end{array}$ \\
\hline $\begin{array}{l}\text { Heuristics } \\
\text { and } \\
\text { Cognitive } \\
\text { Biases }\end{array}$ & $\begin{array}{l}\text { Heuristics and cognitive biases (the two terms are used together as one term and } \\
\text { also synonymously) are defined as processes employed by decision makers in } \\
\text { order to overcome the problem of human information processing capacity being } \\
\text { limited and also to simplify their perceptions of problems (Hodgkinson et al, } \\
\text { 1999; Krabuanrat \& Phelps, 1998; Schwenk, 1984). As such, heuristics and } \\
\text { cognitive biases have been described as a type of intuition (Dane \& Pratt, 2009; } \\
\text { Dane \& Pratt, 2007) and also a perspective of intuition (Kahnemann \& Klein, } \\
\text { 2009). Most commonly, heuristics and cognitive biases are conceptualised as } \\
\text { being a type of intuition, distinct from expert intuition. Heuristic intuition is a } \\
\text { process that utilizes simple-schema (as opposed to expert domain relevant } \\
\text { schema utilized by expert intuition). As such, heuristic intuition uses mental } \\
\text { short-cuts to reduce the complexity of strategic decision making, which can be } \\
\text { useful for reaching quick strategic decisions in uncertain environments, but can } \\
\text { also lead to severe and systematic errors (Tversky \& Kahnemann, 1974). } \\
\text { Examples include illusion of control, law of small numbers, reasoning by } \\
\text { analogy, prior hypothesis bias and exposure to limited alternatives (Schwenk, } \\
\text { 2005). }\end{array}$ \\
\hline $\begin{array}{l}\text { Cognitive } \\
\text { Style }\end{array}$ & $\begin{array}{l}\text { Cognitive style is defined as "individual differences in preferred ways of } \\
\text { organizing and processing information and experience; an individual difference } \\
\text { in how people perceive, think, solve problems, learn, and relate to each other." } \\
\text { (ogilvie \& Hough, 2011: 125). Cognitive style has been conceptualised in terms } \\
\text { of a dual processing system (Pacini \& Epstein, 1999). This conceptualisation } \\
\text { posits that individual's have a preference for either an experiential (intuitive) or } \\
\text { rational (analytic) information processing style. Cognitive style therefore } \\
\text { describes a decision maker's propensity to use intuition, or rationality in the } \\
\text { SDMP. }\end{array}$ \\
\hline Insight & $\begin{array}{l}\text { Insights are "sudden unexpected thoughts that solve problems.” (Hogarth, 2001: } \\
\text { 251). However, insight differs from intuition in that it involves an incubation } \\
\text { period which is preceded by a lengthy deliberate, analytical process (Dane \& } \\
\text { Pratt, 2007; Hogarth, 2001; Shirley \& Langan-Fox, 1996). A further distinction } \\
\text { that has been made is that insight is a conscious process of becoming aware of } \\
\text { the connections supporting a particular decision, whereas intuition reaches } \\
\text { judgments subconsciously (Lieberman, 2000; Sternberg \& Davidson, 1995). }\end{array}$ \\
\hline Instinct & $\begin{array}{l}\text { Instincts are innate biological capabilities and automatic reflexes to stimuli, such } \\
\text { as shutting one's eyes when exposed to bright light (Epstein, 2002; Hogarth, } \\
\text { 2001). Instinct enables individuals to "respond to stimuli in ways that maximize } \\
\text { our chances of survival in the face of a physical threat" (Sadler-Smith \& Shefy, } \\
\text { 2004: 81). Empirical research suggests that intuition is experiential and learnt } \\
\text { which contrasts the innate nature of instinct. }\end{array}$ \\
\hline Guessing & $\begin{array}{l}\text { Guessing is similar to intuition only in terms of its speed. Guessing does not } \\
\text { entail affectively charged judgments nor any kind of non-conscious information } \\
\text { processing, nor does it have the characteristic of certitude associated with }\end{array}$ \\
\hline
\end{tabular}


Submission \#11633

intuitive decisions (Dane \& Pratt, 2007). 


\section{REFERENCES}

Akinci, C., \& Sadler-Smith, E. In press. Intuition in management research: A historical review. International Journal of Management Reviews.

Amason, A. C. 1996. Distinguishing the effects of functional and dysfunctional conflict on strategic decision making: Resolving a paradox for top management teams.” Academy of Management Journal, 39(1): 123-148.

Baum, J. R. \& Wally, S. 2003. Strategic decision speed and firm performance. Strategic Management Journal, 24: 1107-1129.

Bingham, C. B., \& Eisenhardt, K. M. 2011. Rational heuristics: The ‘simple rules' that strategists learn from process experience, Strategic Management Journal, 32(13): 1437-1464.

Bloom, B. S. 1985. Developing Talent in Young People. New York: Ballantine.

Bourgeois III, L. J. \& Eisenhardt, K. M. 1988. Strategic Decision processes in high velocity environments: Four cases in the microcomputer industry. Management Science, 34(7): 816-835.

Brouthers, K. D., Brouthers, L. E., \& Werner, S. 2000. Influences on strategic decision-making in the Dutch financial services industry. Journal of Management, 26(5): 863-883.

Burke, L. A. \& Miller, M. K. 1999. Taking the mystery out of intuitive decision making. Academy of Management Executive, 13: 91-99.

Chassy, P., \& Gobet, F. 2011. A hypothesis about the biological basis of expert intuition. Review of General Psychology, 15(3): 198-212.

Chi, M, T, H. 2006. Two approaches to the study of expert's characteristics in K. A. Ericsson, N. Charness, P. J. Feltovich, \& R. R. Hoffman (Eds.), The Cambridge Handbook of Expertise and Expert Performance: 21-30. New York: Cambridge University Press.

Dane, E., \& Pratt, M. G. 2007. Exploring intuition and its role in managerial decision making.” Academy of Management Review, 32(1): 33-54.

Dane, E., \& Pratt, M. G. 2009. Conceptualizing and measuring intuition: A review of recent trends. In G. P. Hodgkinson \& J. K. Ford (Eds.), International Review of Industrial and Organizational Psychology: 1-40. Chichester: John Wiley \& Sons Limited.

Dane, E. 2011. Capturing intuitions 'in flight': observations from research on attention and mindfulness. In M. Sinclair (Ed.), Handbook of Intuition Research: 217-226.

Cheltenham: Edward Elgar. 
Dayan, M., \& Elbanna, S. 2011. Antecedents of team intuition and its impact on the success of new product development projects. Journal of Product Innovation Management, 28(1): 159-174.

Dean, J. W. \& Sharfman, M. P. 1993. Procedural rationality in the strategic decision making process. Journal of Management Studies, 30: 587-610.

Dean, J. W. \& Sharfman, M. P. 1996. Does decision process matter? A study of strategic decision making effectiveness. Academy of Management Journal, 39: 368-396.

Dess, G. G. \& Beard, D. W. 1984. Dimensions of organizational task environments. Administrative Science Quarterly, 29: 52-73.

Dijksterhuis, A. 2004. Think different: The merits of unconscious thought in preference development and decision making. Journal of Personality and Social Psychology, 87: 586-598.

Drillings, M., \& Serfaty, D. 1997. Naturalistic decision making in command and control. In C. E. Zsambok and G. Klein (Eds.), Naturalistic Decision Making: 71-80. Mawah, NJ: LEA.

Duhaime, I. M. \& Schwenk, C. R. 1985. Conjectures on cognitive simplification in acquisition and divestment decision making. Academy of Management Review, 10(2): 287-295.

Dunwoody, P. T., Haarbauer, E., Mahan, R. P., Marino, C. \& Tang, C. 2000. Cognitive adaptation and its consequences: A test of cognitive continuum theory. Journal of Behavioural Decision Making, 13: 35-54.

Eisenhardt, K. M. 1989. Making fast strategic decisions in high-velocity environments. Academy of Management Journal, 32 (2): 543-576.

Eisenhardt, K. M. \& Zbraracki, M. J. 1992. Strategic decision making. Strategic Management Journal, 13: 17-37.

Elbanna, S. 2003. Strategic decision-making: Antecedents and outcomes. Unpublished doctoral dissertation, The University of Birmingham, UK.

Elbanna, S. 2006. Strategic decision-making: process perspectives. International Journal of Management Reviews, 8(1): 1-20.

Elbanna, S. \& Child, J. 2007a. Influences on strategic decision effectiveness: Development and test of an integrative model. Strategic Management Journal, 28: 431-453.

Elbanna, S. \& Child, J. 2007b. The influence of decision, environmental and firm characteristics on the rationality of strategic decision making. Journal of Management Studies, 44: 561591. 
Epstein, S. 1994. Integration of the cognitive and psychodynamic unconscious. American Psychologist, 49: 709-74.

Epstein, S., Pacini, R., Heier, H., \& Denes-Raj. V. 1996. Individual differences in intuitiveexperiential and analytical-rational thinking styles. Journal of Personality and Social Psychology, 71(2): 390-405.

Epstein, S. 1998. Emotions and psychology from the perspective of cognitive-experiential selftheory. In W. F. Flack \& J. D. Laird (Eds.), Emotions in Psychopathology: Theory and Research: 111-137. New York: Oxford University Press.

Epstein, S. 2002. Cognitive-experiential self-theory of personality. In T. Millon \& M. J. Lerner (Eds). Comprehensive Handbook of Psychology. Volume 5: Personality and Social Psychology: 159-184. Hoboken, NJ: Wiley.

Epstein, S. 2010. Demystifying intuition: what it is, what it does, and how it does it. Psychological Inquiry, 21: 295-312.

Ericsson, K. A. \& Charness, N. 1994. Expert performance. American Psychologist, 49: 725747.

Ericsson, K. A., Prietula, M. J. \& Cokely, E. T. 2007. The making of an expert. Harvard Business Review, July-August 2007: 1-8.

Farjoun, M., \& Levin, M. 2011. A fractal approach to industry dynamism. Organization Studies, 32(6): 825-851.

Fiske, S. T., \& Taylor, S. E. 1991. Social Cognition (2 ${ }^{\text {nd }}$ ed.). New York: McGraw-Hill.

Forbes, D. P. 2007. Reconsidering the strategic implications of decision comprehensiveness. Academy of Management Review, 32(2): 361-376.

Fredrickson, J. W. \& Mitchell, T. R. 1984. Strategic decision processes: Comprehensiveness in an industry with an unstable environment. Academy of Management Journal, 27(2): 399423.

Goll, I. \& Rasheed, A. A. 1997. Rational decision-making and firm performance: The moderating role of environment. Strategic Management Journal, 18(7): 583-591.

Goll, I., \& Rasheed, A. A. 2005. The relationship between top management demographic characteristics, rational decision making, environmental munificence, and firm performance. Organization studies, 26(7): 999-1023.

Hambrick, D. C., \& Mason, P. A. 1984. Upper echelons: The organization as a reflection of its top management. The Academy of Management Review, 9(2): 193-206.

Hayashi, A. M. 2001. When to trust your gut. Harvard Business Review, 79(2):59-65. 
Hodgkinson, G. P., Bown, N. J., Maule, J. A., Glaister, K. W., \& Pearman, A. D. 1999. Breaking the frame: An analysis of strategic cognition and decision making under uncertainty. Strategic Management Journal, 20: 977-985.

Hodgkinson, G. P., Langan-Fox, J., \& Sadler-Smith, E. 2008. Intuition: A fundamental bridging construct in the behavioural sciences. British Journal of Psychology, 99: 1-27.

Hodgkinson, G. P., Sadler-Smith, E., Burke, L. A., Claxton, G., \& Sparrow, P. R. 2009. Intuition in organizations: Implications for strategic management. Long Range Planning, 42: 277297.

Hodgkinson, G. P., \& Healey, M. P. 2011. Psychological foundations of dynamic capabilities: Reflexion and reflection in strategic management. Strategic Management Journal, 32(13): 1500-1516.

Hogarth, R. M. 2001. Educating Intuition. Chicago: University of Chicago Press.

Hough, J. R. \& White, M. A. 2003. Environmental dynamism and strategic decision making rationality: An examination at the decision level. Strategic Management Journal, 24: 481-489.

Hough, J. R. \& ogilvie, d. t. 2005. An empirical test of cognitive style and strategic decision outcomes. Journal of Management Studies, 42(2): 417-448.

Judge, W. Q. \& Miller, A. 1991. Antecedents and outcomes of decision speed in different environmental contexts. Academy of Management Journal. 34: 449 - 463.

Jung, C. G. 1933. Psychological Types. New York: Harcourt, Brace and Company.

Kaempf, G. L., Klein, G., Thorsden, M. L., \& Wolf, S. 1996. Decision making in complex naval command-and-control environments. Human Factors, 38:220-231.

Kahnemann, D. 2003. A Perspective on judgment and choice: Mapping bounded rationality. American Psychologist, 58(9): 697-720.

Kahneman, D. \& Klein, G. 2009. Conditions for intuitive expertise. American Psychologist, 64: 515-526.

Kahnemann, D. 2011. Thinking, Fast and Slow. London: Allen Lane.

Khatri, N. \& Ng, H. A. 2000. The role of intuition in strategic decision making. Human Relations, 53: 57-86.

Kilduff, M., Angelmar, R., \& Mehra A. 2000. Top management-team diversity and firm performance: Examining the role of cognitions. Organization Science. 11(1): 21-34.

Klein, G. 1998. Sources of Power: How People Make Decisions. Cambridge, MA: MIT Press. 
Klein, G. 2003. Intuition at work. New York: Doubleday.

Krabuanrat, K., \& Phelps, R. 1998. Heuristics and rationality in strategic decision making: An exploratory study. Journal of Business Research, 41: 83-93.

Lawrence, B. S. 1997. The black box of organizational demography. Organization Science, 8(1): $1-22$.

Lieberman, M. D. 2000. Intuition: A social cognitive neuroscience approach. Psychological bulletin. 126(1): 109-137.

Miller, C. C. \& Ireland, R. D. 2005. Intuition in strategic decision making: Friend or foe in the fast-paced $21^{\text {st }}$ century? Academy of Management Executive, 19: 19-30

Mintzberg, H., Raisinghani, D. \& Theoret, A. 1976. The structure of unstructured decision processes. Administrative Science Quarterly. 21: 246 - 275.

Mintzberg, H. 1994a. Rethinking strategic planning part I: Pitfalls and fallacies. Long Range Planning, 27(3): 12-21.

Mintzberg, H. 1994b. Rethinking strategic planning part II: New roles for planners. Long Range Planning, 27(3): 22-30.

Mitchell, J. R., Shepherd, D. A. \& Sharfman, M. P. 2011. Erratic strategic decisions: When and why managers are inconsistent in strategic decision making. Strategic Management Journal, 32: (683-704).

Nadkarni, S., \& Herrmann, P. 2010. CEO personality, strategic flexibility, and firm performance: The case of the Indian business process outsourcing industry. Academy of Management Journal, 53(5): 1050-1073

ogilvie, d. t. \& Hough, J. R. 2011. Strategic decisions and cognitive style: A non-US perspective. In T. Garcia Merino \& Santos-Alvarez (Eds.), Managerial Cognition and Strategic Management: Rethinking Internationalization Strategies: 125-144. New York: Nova Science Publishers Inc.

Orasanu, J., \& Connolly, T. 1995. The reinvention of decision making. In G. A. Klein, J. Orasanu, R. Calderwood., \& Zsambok, C. E. (Eds.), Decision Making in Action: Models and Methods:3-20. Norwood, NJ: Ablex Publishing Corporation.

Pacini, R. \& Epstein, S. 1999. The relation of rational and experiential information processing styles to personality, basic beliefs, and the ratio-bias problem. Journal of Personality and Social Psychology, 76: 972-987.

Papadakis, V. M. \& Barwise, P. 1997. Strategic Decisions. Boston: Kluwer Academic Publishers 
Papadikis, V. M., Lioukas, S. \& Chambers, D. 1998. Strategic decision making processes: The role of management and context. Strategic Management Journal, 19: 115-147.

Papadakis, V. M., Thanos, T., \& Barwise, P. 2010. Research on strategic decisions: Taking stock and looking ahead. In P. C. Nutt \& D. Wilson (Eds.), Handbook of Decision Making: 3170. Chichester: Wiley.

Priem, R. L., Lyon, D. W., \& Dess, G. G. 1999. Inherent limitations of demographic proxies in top management team heterogeneity research. Journal of Management, 25:935-953.

Quinn, B. 1980. Strategies for Change: Logical Incrementalism. Homewood Ill: R.D. Irwin.

Rorty, R. 1967. Intuition. In P. Edwards (Ed.), Encyclopaedia of Philosophy: 204-212. New York: Macmillan.

Sadler-Smith, E. \& Shefy, E. 2004. The intuitive executive: Understanding and applying 'gut feel’ in decision-making. Academy of Management Executive, 18: 76-91.

Salas, E., Rosen, M. A. \& DiazGranados, D. 2010. Expertise-based intuition and decision making in organizations. Journal of Management, 36: 941-973.

Schwenk, C. R. 1984. Cognitive simplification processes in strategic decision making. Strategic Management Journal, 5: 111-128.

Schwenk, C. R. 1988. The cognitive perspective on strategic decision making. Journal of Management Studies, 25(1): 41-55.

Schwenk, C. R. 2005. The cognitive perspective on strategic decision making. In G. Salaman, J. Storey \& J. Billsbery (Eds.), Strategic Human Resource Management Theory and Practice: A Reader: 78-90. London: SAGE

Shanteau, J. 1992. Competence in experts: The role of task characteristics. Organizational Behaviour and Human Decision Processes, 53: 252-262.

Shanteau, J., Weiss, D. J., Thomas, R. P. \& Pounds, J. C. 2002. Performance-based assessment of expertise: How to decide if someone is an expert or not. European Journal of Operational Research, 136: 253-263.

Shirely, D. A. \& Langan-Fox, J. 1996. Intuition: A review of the literature. Psychological Reports, 79: 563-584.

Simon, H. A. 1987. Making management decisions: The role of intuition and emotion. Academy of Management Executive, 1(1): 57-64

Simon, H. A. 1992. What is an “explanation” of behaviour? Psychological Science, 3: 150-161. 
Simonton, D. K. 2006. Histriometric methods. In K. A. Ericsson, N. Charness, P. J. Feltovich, \& R. R. Hoffman (Eds.), The Cambridge Handbook of Expertise and Expert Performance: 319-335. New York: Cambridge University Press.

Sinclair, M., \& Ashkanasy, N. M. 2005. Intuition: Myth of decision making tool? Management Learning, 36(3): 353-370.

Sinclair, M., Sadler-Smith, E., \& Hodgkinson, G. P. 2009. The role of intuition in strategicdecision making in L. A. Costanzo, \& R. B. MacKay (Eds.), Handbook of Research on Strategy and Foresight: 393-417. Cheltenham: Edward Elgar Publishing Limited.

Sinclair, M. 2010. Misconceptions about intuition. Psychological Inquiry, 21: 378-386.

Sonenshein, S. 2010. The role of construction, intuition and justification in responding to ethical issues at work: The sensemaking-intuition model. Academy of Management Review, 32(4): 1022-1040.

Stahl, M. J., \& Grigsby, D. W. 1992. Strategic management for decision-making. Boston: PWS-Kent.

Stenberg, R. J. \& Davidson, J. E. 1995. The Nature of Insight. Cambridge MA: MIT Press.

Stubbart, C. I. 1989. Managerial cognition: A missing link in strategic management research.” Journal of Management Studies, 26: 325-347.

Tversky, A., \& Kahnemann, D. 1974. Judgment under uncertainty: Heuristics and biases. Science, 185: 1124-1131.

Wally, S., \& Baum, J. R. 1997. Timing and intuition in strategic decision making in V. Papadakis \& P. Barwise (Eds.), Strategic Decisions: 95-106. Boston: Kluwer Academic Publishers.

Westcott, M. R., \& Ranzoni, J. H. 1963. Correlates of intuitive thinking. Psychological Reports, 12: $595-613$

Wilson, D. 2003. Strategy as decision-making in S. Cummings \& D. Wilson (Eds.), Images of Strategy: 383-410. Oxford: Blackwell.

Winter, S. 1981. Attention allocation and input proportions. Journal of Economic Behaviour and Organization, 2(1): 31-46. 